\title{
Analysis of chromophores in stained-glass windows using Visible Hyperspectral Imaging in-situ
}

Teresa Palomar ${ }^{1,2}$, Chiara Grazia ${ }^{3}$, Isabel Pombo Cardoso ${ }^{4,5}$, Marcia Vilarigues ${ }^{1,4}$, Costanza Miliani $^{3,6}$, Aldo Romani ${ }^{3,6}$

${ }^{1}$ Unidade de investigação VICARTE-Vidro e Cerâmica para as Artes, Campus de Caparica, FCTUNL, Quinta da Torre, 2829-516 Caparica, Portugal

${ }^{2}$ Instituto de Cerámica y Vidrio, Consejo Superior de Investigaciones Científicas (ICV-CSIC), c/ Kelsen 5, Campus de Cantoblanco, 28049 Madrid, Spain

${ }^{3}$ SMAArt Centre, c/o Dipartimento di Chimica, Biologia e Biotecnologie, Università degli Studi di Perugia, Via Elce di Sotto, 8, 06123, Perugia, Italy

${ }^{4}$ Dpto. de Conservação e Restauro, Universidade NOVA de Lisboa, Campus de Caparica, FCTUNL, Quinta da Torre, 2829-516 Caparica, Portugal

${ }^{5}$ LAQV-REQUIMTE, Universidade NOVA de Lisboa, Campus de Caparica, FCT-UNL, Quinta da Torre, 2829-516 Caparica, Portugal

${ }^{6}$ CNR-ISTM c/o Dipartimento di Chimica, Biologia e Biotecnologie, Università degli Studi di Perugia, Via Elce di Sotto, 8, 06123, Perugia, Italy

*Corresponding author, e-mail: t.palomar@csic.es (T. Palomar)

\section{Abstract}

This work presents the implementation of Visible Hyperspectral Imaging for the in-situ analysis of glass chromophores in two glass windows from the Casa-Museu Dr. Anastácio Gonçalves (Lisbon, Portugal). The measurements were taken inside the building using natural sunlight as the illumination source. In addition, advantages and disadvantages of the followed methodology are discussed.

The Dining Room glass window presents glasses colored in bulk with iron, manganese, cobalt, copper, and chromium; silver staining was also detected and was used to create the yellow and orange colors. The Atelier panel was produced with uncolored glasses painted with grisaille and enamels; the chromophores identified are similar to the species identified in the Dining Room panel. 


\section{Graphical abstract}

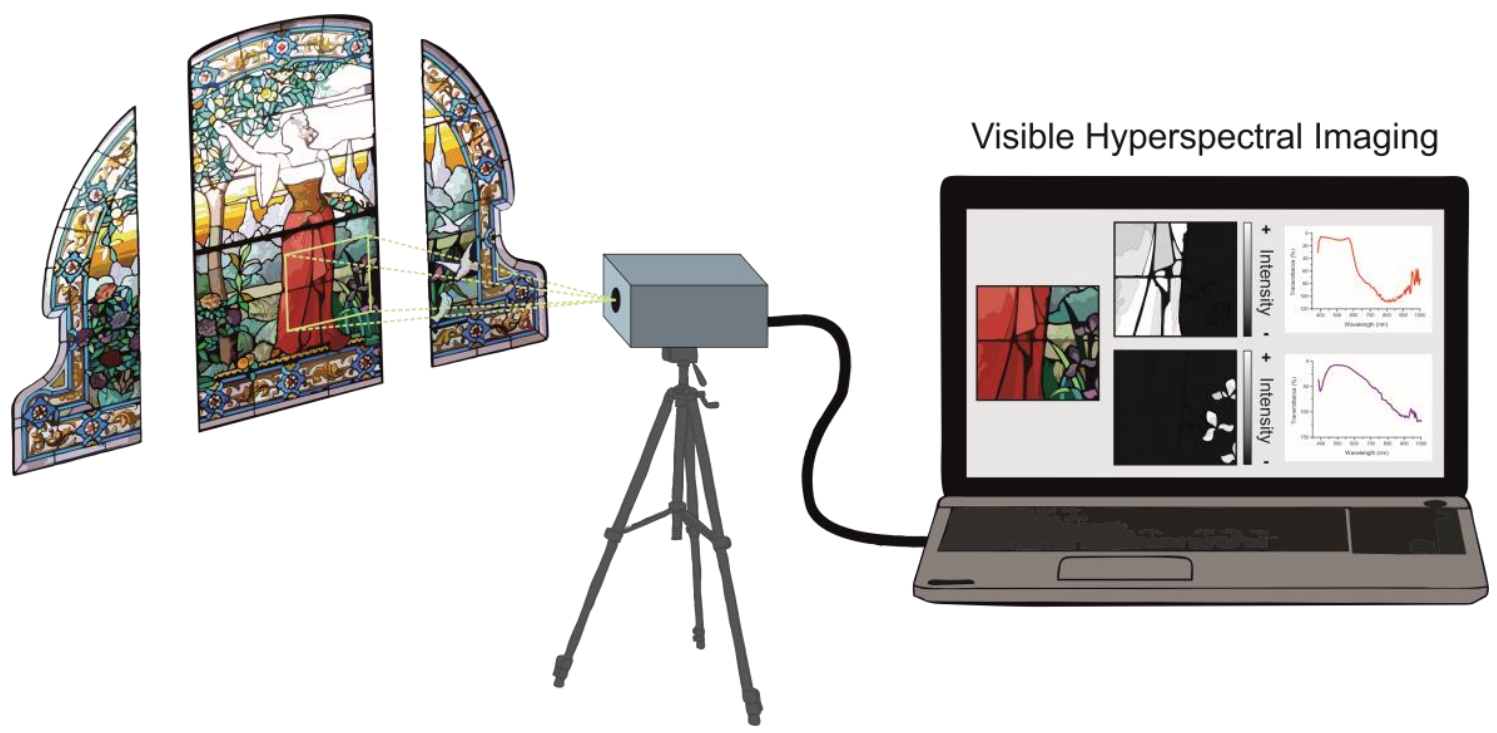

\section{Keywords}

Stained-glass windows, colored glass, enamels, chromophores, Visible Hyperspectral Imaging.

(C) 2019. This manuscript version is made available under the CC-BY-NC-ND 4.0 license http://creativecommons.org/licenses/by-nc-nd/4.0/

Published in Spectrochimica Acta Part A: Molecular and Biomolecular Spectroscopy 223 (2019) 117378, 1-9 https://doi.org/10.1016/i.saa.2019.117378 


\section{Highlights}

1. Glass chromophores were detected in-situ by Visible Hyperspectral Imaging using sunlight as illumination source.

2. The technique permitted the overall analysis of each glass of the window in few hours.

3. Despite the highly optical density of enamels compared to colored bulk glasses, the technique allows the characterization of both. 


\section{Introduction}

The analysis of stained glass, namely through the identification of the species responsible for the different colors, allows information to be disclosed regarding the production technology, such as the use of enamels, grisailles or silver stain; and even permits restorations to be detected due to the use of modern chromophores such as the chromium.

From the physical point of view, glass color is the result of the interaction of the light with ionic, molecular, colloidal or microcrystalline species in the glass, which are commonly known as chromophores [1]. The cations of the transition elements $\left(\mathrm{Mn}^{2+}, \mathrm{Mn}^{3+}, \mathrm{Fe}^{2+}, \mathrm{Fe}^{3+}, \mathrm{Co}^{2+}\right.$, etc.) are the most common group of chromophores. Their valence electrons can be promoted from the ground state into a higher energy orbital through the absorption of photons. The absorbed energy, characteristic of each ion, generally corresponds to frequencies in and near the visible region of the electromagnetic spectra $(400-700 \mathrm{~nm})$, conferring to the glass the complementary color to the wavelengths absorbed [1, 2]. This energy depends on the electromagnetic configuration of the cations and the free energy levels in the incompleted $d$ orbitals of their electronic layer. Groups of atoms and/or molecules in a colloidal or microcrystalline state form the second commonest group of chromophores. In this case, the color is produced by a synergic mechanism of absorption-dispersion of the light and depends on the nature of the chromophore, its size and its concentration in the glass. The most common ones are gold and copper ruby glasses, and the yellow silver staining. Finally, the last group of chromophores is the one formed by relatively large compounds such as particles of $\mathrm{Cu}_{2} \mathrm{O}$ or $\mathrm{Cr}_{2} \mathrm{O}_{3}[1,3]$.

In spite of the importance of the color analysis in the characterization of stained-glass windows, its study has limitations. Optical spectroscopy in the UV-VIS-NIR range is the most frequent technique used for the analysis of chromophores, usually in absorption or transmission mode [4-12], because it permits to identify the chemical state of the chromophores and the nature of the coloring phenomenon; but it is a destructive technique because it needs a thin and polished sample. For this reason, only glass fragments rejected during the restoration process have been generally analyzed $[4,8,9,13-16]$. It is also possible to perform this analysis by reflectance [17], but the spectra normally have lower quality [18]. Portable setups developed in the last years, partially allow this limitation to be overcome, enabling glass samples to be analyzed directly on a stained-glass window panel without sampling [19-21], but they generally need to remove the panel from its original location. A first use of the sunlight as excitation source with point measurements setup have been done with a portable instrument in-situ [22]. 
Some studies have also identified the chromophores on glass fragments from stained-glass windows analyzing the minor and trace elements on the glasses with electron probe microanalysis (EPMA) [23], proton-induced X-ray or $\psi$-ray emission (PIXE-PIGE) [24, 25] or laser ablation inductively coupled plasma mass spectrometry (LA-ICP-MS) [26-28]. Nevertheless, these elemental techniques are not suitable to analyze the glass color since some elements, such as iron or manganese, have species with different oxidation states that can produce different colorations in the glass. Thus, the interaction of the chromophores in the glass batch with the atmosphere inside the furnace has a significant impact on the redox equilibrium between the different species, inducing different glass colorations [29-31]. Some of these studies were, also, complemented by electron paramagnetic resonance (EPR) [23], which is a specific technique for the detection of paramagnetic ions present in different oxidation states in the glass fragments; or transmission electron microscope (TEM) to observe the metallic nanoparticles [25].

In order to make a comprehensive analysis of stained-glass windows, some studies on entire glass panels were carried out with macro X-ray fluorescence (MA-XRF) scanning. The main objective was to distinguish different glass types and surface alteration products within the same panel [32-34]; additionally, the chromophores of the glass fragments were also analyzed in the interior and exterior side of the glass panel to identify colored bulk glass, flash glass or yellow silver staining. This procedure implies the removal of the stained-glass windows from its original location and performance of analysis panel by panel. Another technique which permits the overall analysis of an object is Visible Hyperspectral Imaging, which allows the inspection of a wide surface in a very short time. This technique has been widely applied, in reflectance acquisition mode, to determine pigments on different substrates such as canvas, paper or stone [35-40]; however, studies on historical glasses are scarce, probably due to instrumental difficulties [21]. Indeed, the most common procedure was to remove the stained-glass windows from their original site, being analyzed in the laboratory before the restoration process, working in transmission mode with artificial illumination.

The main objective of this research was to establish for the first time the methodology for the in-situ characterization of glass color in stained-glass windows by Visible Hyperspectral Imaging with natural sunlight as illumination, and to apply it for the characterization of chromophores in two Art Nouveau glass windows. 


\section{Materials and methods}

\subsection{The stained-glass windows}

Two different Art Nouveau glass windows from the Casa-Museu Dr. Anastácio Gonçalves (Lisbon, Portugal) were analyzed by Visible Hyperspectral Imaging. They were realized by the Societé Artistique de Peinture sur Verre in 1904. The Dining room stained-glass window (formed by three windows of $188 \times 64 \mathrm{~cm}, 210 \times 98 \mathrm{~cm}$ and $188 \times 64 \mathrm{~cm}$ placed at $99 \mathrm{~cm}$ from the ground) is composed by colored glass fragments painted with grisailles and lead cames defining the contours of the figures (Fig. 1 a). This stained-glass window is placed with south-west orientation and it is directly illuminated for six hours by the sun in the summer solstice. The Atelier window (formed by six panels placed at $60 \mathrm{~cm}$ from the ground) was elaborated with hammered glasses (rectangular pieces of $10 \times 15 \mathrm{~cm}$ ) painted with grisaille and enamels (Fig. $1 \mathrm{~b}$ ). This window is placed with north-west orientation and it is directly illuminated for four hours by the sun in the summer solstice.
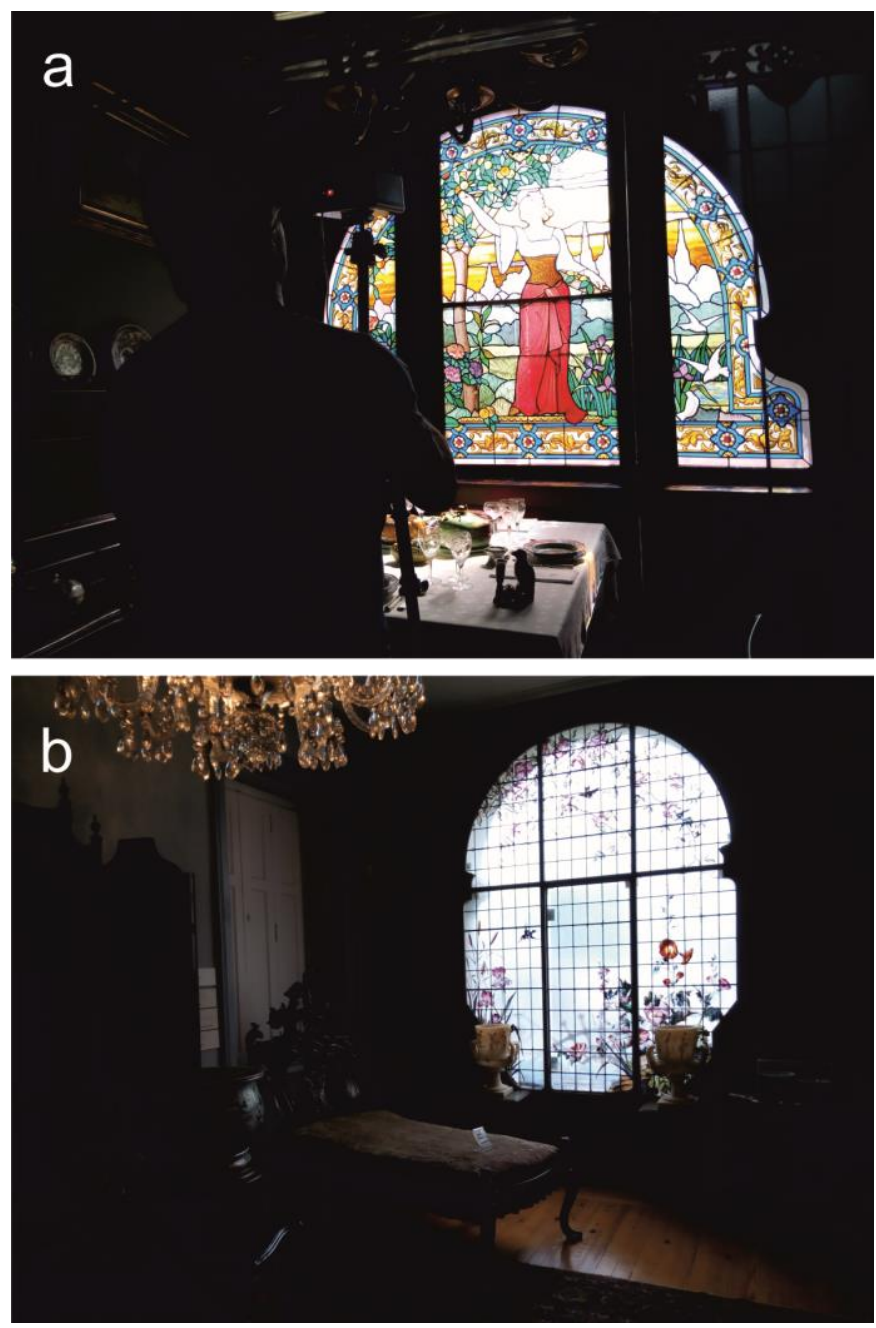

Fig. 1. Glass windows in the Casa-Museu Dr. Anastácio Gonçalves in the a) Dining room, b) Atelier. 


\subsection{Visible Hyperspectral Imaging}

The Visible Hyperspectral Imaging measurements were performed using a Surface Optics Corporation SOC 710 camera. The system utilizes a whiskbroom line scanner producing a $696 \times 520$ pixels hypercube in the $400-1000 \mathrm{~nm}$ spectral range with 128 bands and about $4.5 \mathrm{~nm}$ spectral resolution. The lateral resolution can be continuously modulated by adjustable focal length of the mounted objective moving the camera at the suitable distance. In the current setup, the camera, mounted on a photographic tripod, was positioned at about $1.8 \mathrm{~m}$ from the windows surface obtaining about $20 \times 30 \mathrm{~cm}$ single frames. With these conditions, each single frame is defined by about $70 \mathrm{dpi}$ resolution. The more than 100 single frames collected (containing about 36 million spectra) in order to cover both the whole windows, have afterwards been assembled by means of mosaicing software kindly provided by Dr. John Delaney, National Gallery of Art, Washington. By this way, we obtained four and six reconstructed hypercubes for the Dining Room and Atelier, respectively. Each pixel of these hypercubes contains an irradiance calibrated spectrum of the solar light in the $400-1000 \mathrm{~nm}$ spectral range, modified by the color of the glass in the physical position which corresponds to that pixel in the reconstructed image.

Visible analyses were also undertaken by UV-vis spectroscopy in absorbance mode using the AvaSpec-2048-SPU optical fibers spectrophotometer with natural sunlight as light source. The AvaSoft software controlled the acquisition of the spectra in the 200-1100 nm range. Measurements were performed using $10 \mathrm{~ms}$ of integration time with 25 accumulations. These results allow us to validate the spectral features obtained with hyperspectral measurements as described in the following.

\section{Results and Discussion}

\subsection{Implementation of the methodology}

The raw reconstructed hypercubes have been elaborated using ENVI software in order to extract the spectral features of the chromophores responsible for the colors of the windows. The first operation performed consists in the spectral calibration of the irradiance spectra collected by the camera. For this purpose, a reference area of the hypercube, owning a known transmittance spectrum, must be selected and, based on its spectral properties, for all the images' pixels, the software performs a transformation from irradiance to transmittance spectrum. For all the data, a transparent uncolored area of the investigated window has been chosen as reference for the transmittance calibration, assuming it owns a flat $100 \%$ transmittance in the whole spectral 
range. As a good homogeneity of the glass optical properties on the same window can be reasonably assumed, this should represent the best choice in order to obtain a correct spectral shape for all the colored materials present. This is surely true under constant homogenous illumination without any changes in both intensity and spectral distribution. In the present case study, the sunlight intensity used as illumination source changes, sometimes drastically, mainly due to the presence of moving clouds. This natural unavoidable event can affect both the single frame collection (which requires about one minute to be performed in the present setup) and the luminous exposition of the different frames assembled in the reconstructed images by the mosaicing software. For this reason, the spectral transmittance gain of the calibrated spectra can be different and often greater than the $100 \%$ physical limit. This experimental evidence is clearly shown in Fig. 2.

a

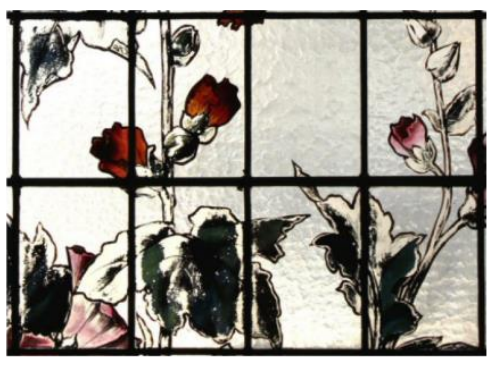

d

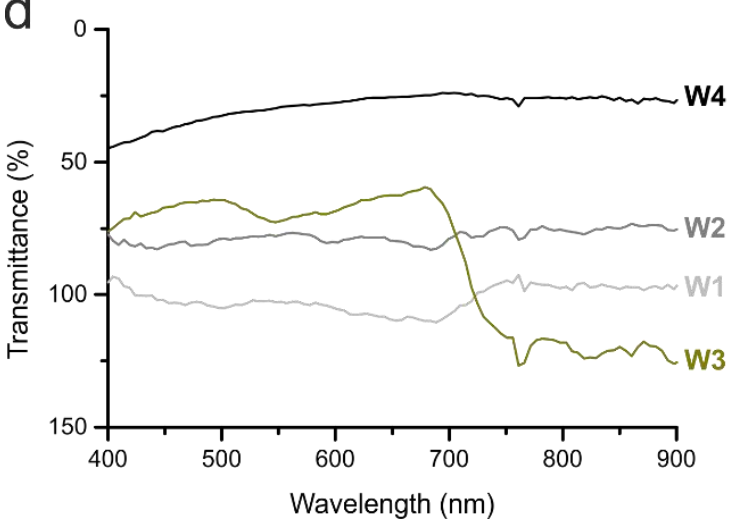

b

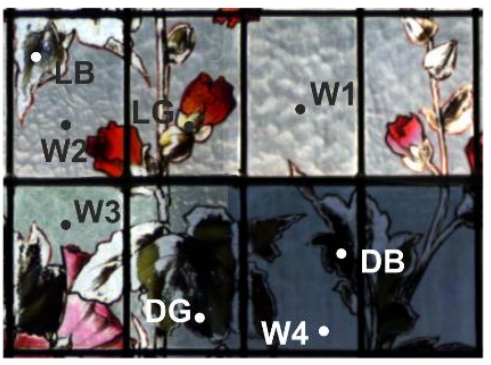

C

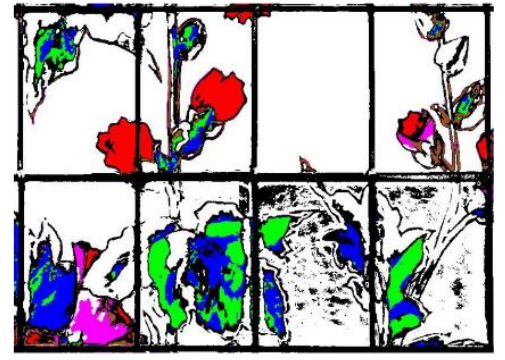

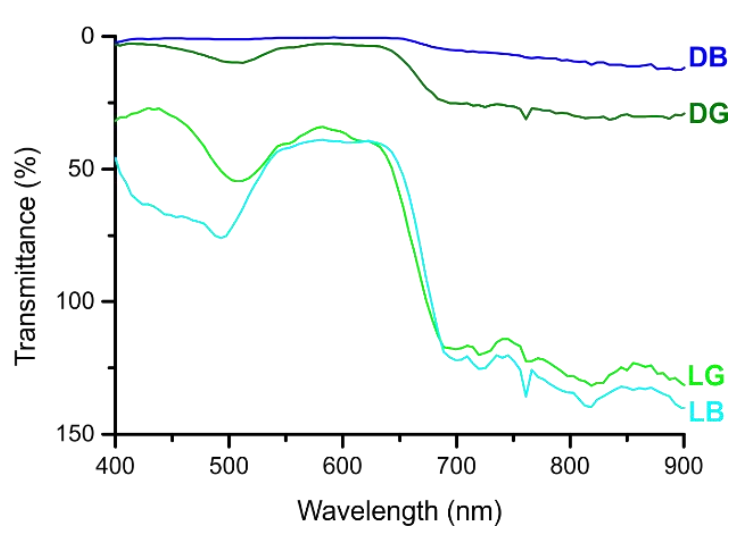

Fig. 2. Images of a detail from the Atelier window: a) digital photo, b) RGB reconstruction from the acquired hyperspectral cubes, c) false color mapping of the different chromophores. d) Spectra obtained from a $5 \times 5$ pixel averaged areas listed in Fig. 2 b.

Fig. $2 \mathrm{~b}$ displays the mosaicing of four hypercubes; by looking to the transparent glass areas it appears that the illumination intensity has changed during the acquisition. Consistently, the transmittance calculated on the basis of the initial reference can vary markedly, as shown in Fig. $2 \mathrm{~d}$. If the lightening condition are close to the ones occurring during the reference acquisition, the calculated values of transmittance will be close to $100 \%$, as exemplified by W1. On the contrary, a lower light intensity will produce lower calculated transmittance values, such as in 
W2 and W4. Moreover, the presence of external objects (such as vegetation) contributes to the spectra, such as in W3.

Fortunately, these interferences do not affect the spectral features of each different color, at least for what concerns the most intense and saturated colors. In fact, despite the differences in the illumination, spectra apparently different such as those shown in the right plot of Fig. $2 \mathrm{~d}$, can be reasonably treated by the mapping software choosing the correct value of the Spectral Angle Mapper parameters (see the following for details). In the example, the spectra of two chromophores (namely green and blue) obtained from strongly illuminated areas (LG and LB for the green and the blue, respectively) are compared with the spectra of the same color obtained in a very dark area (DG and DB for the green and the blue, respectively). As it is clearly shown comparing the false color mapping (Fig. 2 c) with the digital photo (Fig. 2 a), the mapping software is able to correlate the visible color with the chromophore responsible for its production in spite of the illumination condition in which they have obtained. Just in the case of very light colored parts of the windows, the change in illumination intensity together with external objects contribution (decorative bars positioned outside the windows, vegetation, etc.) sometimes lead to local spectral distortion, making it more difficult to obtain the spatial distribution of similar materials. Nevertheless, this did not prevent a satisfactory description and distribution of the chromophores as shown in Fig. $2 \mathrm{c}$ and in general in the following.

The following step was the selection of the meaningful endmembers among the whole family of spectra present in each cube, able to describe all the different materials present. ENVI can perform this search through a preliminary estimation of noise statistics from data followed by a Pixel Purity Index construction, which groups the pixels by their spectral contribution at each wavelength. This obtained result is then treated by an autocluster function, which extracts the main different spectral features present on the hypercube. The obtained spectral database can be manually implemented with spectra considered relevant, selected by the operator, which the software was not able to distinguish. The number of endmembers obtained for the description of the different colors present in the glasses is 19 for the Dining Room and 8 for the Atelier and their chemical nature is reported in Table 1. 
Table 1. Chromophores assignment in the visible region for different colored silicate glasses

\begin{tabular}{llll}
\hline Color & Assignment & Meaningful band(s) $(\mathrm{nm})$ & References \\
\hline Blue/Light blue & $\mathrm{Co}^{2+}$ & $540,590,640$ & {$[1,2,41-43]$} \\
Violet/Pink & $\mathrm{Mn}^{3+}$ & 500 & {$[1,2,43-47]$} \\
Emerald green & $\mathrm{Cr}^{3+}$ & $450,630,650,675$ & {$[1,41,43]$} \\
& $\mathrm{Cr}^{6+}$ & 365 & \\
Turquoise green & $\mathrm{Cu}^{2+}$ & 790 & {$[1,2,43]$} \\
Green & $\mathrm{Fe}^{2+}$ & 440,1100 & {$[1,2,48]$} \\
& $\mathrm{Fe}^{3+}$ & $380,420,440$ & \\
Yellow/Orange & $\mathrm{Ag}^{0}$ & $400-450$ & {$[1,5,14,49-51]$} \\
Red & $\mathrm{Cu}^{0}$ & 560 & {$[1,52]$} \\
Brown/Light brown & $\mathrm{FeO}_{3} \mathrm{~S}$ & 295,425 & {$[1,3,53-55]$} \\
\hline
\end{tabular}

Finally, the spectral library of endmembers obtained can be mapped, by means of the Spectral Angle Mapper algorithm present in ENVI, obtaining a false color image where to each color corresponds a different material characterized by its own spectrum. Spectral Angle Mapper is a physically-based spectral classification that uses an n-D angle to match pixels to reference spectra. The algorithm determines the spectral similarity between two spectra by calculating the angle between the spectra and treating them as vectors in a space with dimensionality equal to the number of bands. No spectra pre-processing has needed for the elaboration above described.

As validation of the goodness of the implemented methodology described above, a comparison among the spectra of the endmembers obtained by hyperspectral imaging and conventional transmittance spectrophotometer was performed. The spectra obtained by the optical fiber UVvis spectrometer and by the Visible Hyperspectral Imaging system were very similar in shape. In Fig. $3 \mathrm{~b}$, the spectra collected by the two instrumentation are compared and the corresponding spatial distribution of the identified chromophores is shown in detail picture on the Fig. 3 a. The differences in transmittance between the two instruments are attributable to the differences in illumination and collection [56]. The great advantage of the Visible Hyperspectral Imaging system is to allow the mapping of large areas in a relatively short time, to obtain the spectra from each pixel and to create maps for specific spectra (Fig. 3 a). 

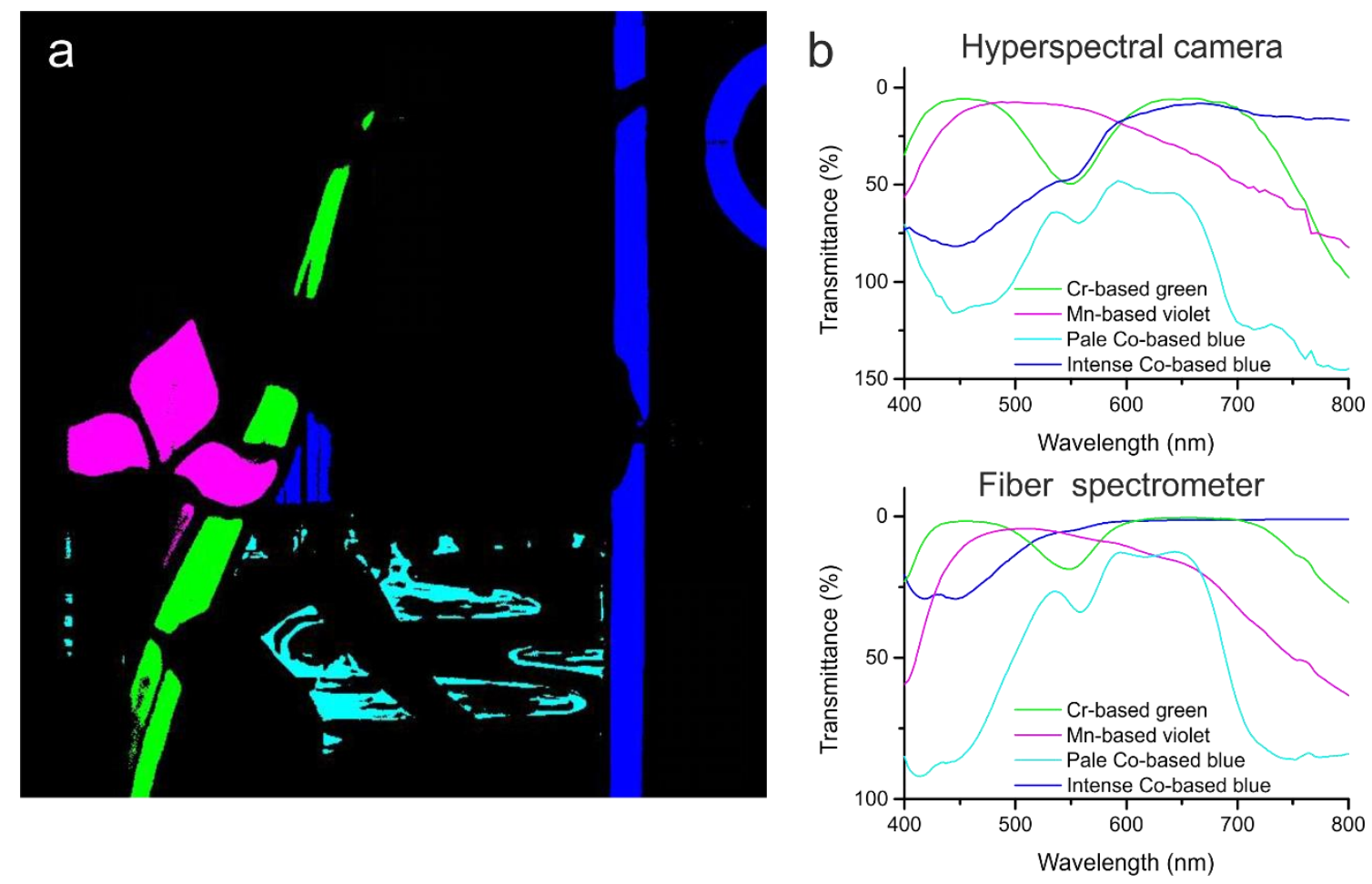

Fig. 3. a) Mapping of the green, violet, pale blue and blue areas made by the Visible Hyperspectral Imaging system based on their spectral features. b) Spectra obtained by the Visible Hyperspectral Imaging system and the optical fiber spectrometer on the same colored glasses. The chromophores identification is based on the discussion reported below. 


\subsection{Application to real case studies}

\subsubsection{Dining room window}

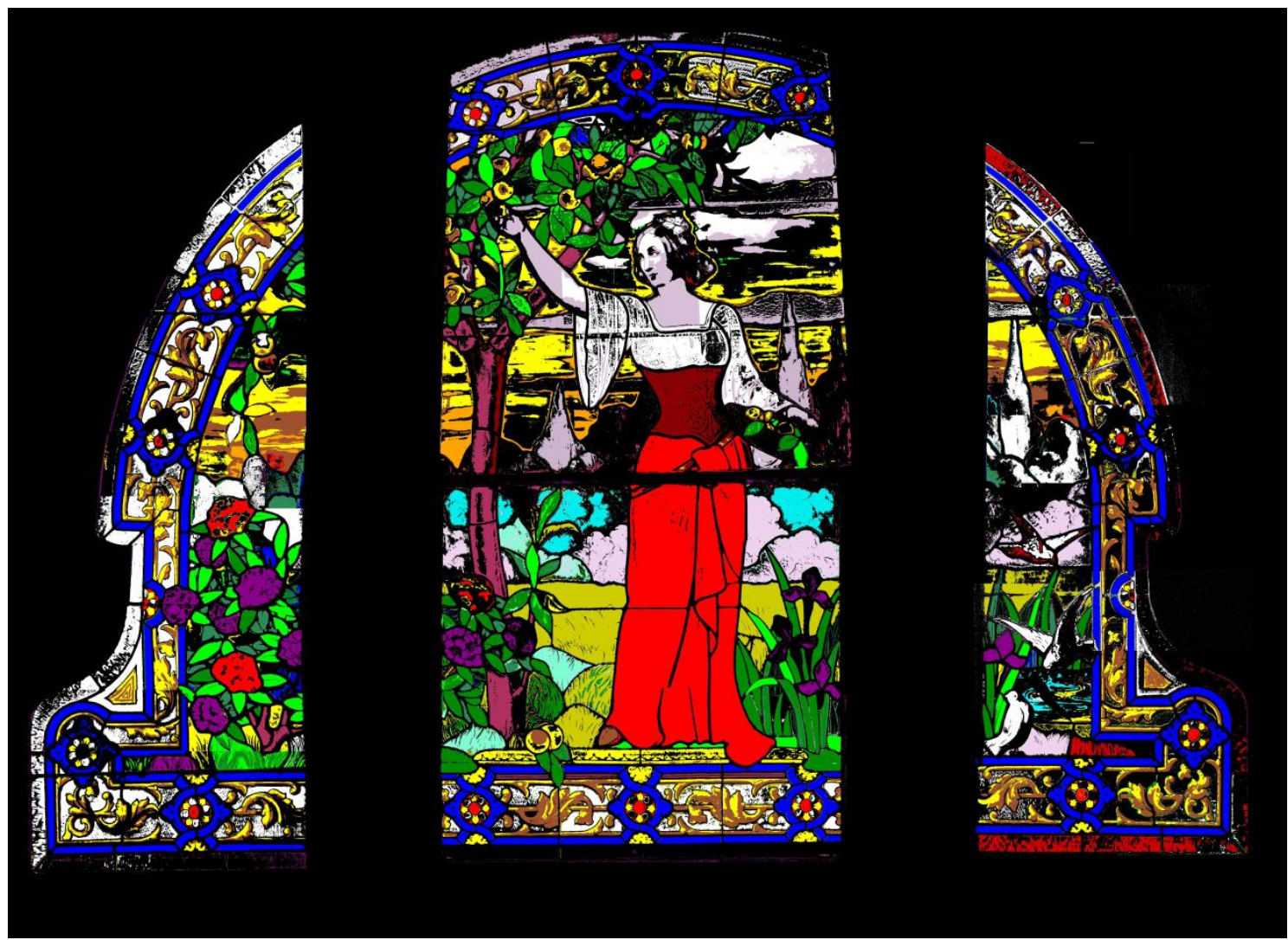

Fig. 4. False-color mapping of the different chromophores in the stained-glass window from the Dining room of the Casa-Museu Dr. Anastácio Gonçalves (Lisbon). The transmittance spectra from each false-color are represented in Fig. 5 (saturated colors) and Fig. 6 (light colors).

The stained-glass window in the Dining room of the Casa-Museu Dr. Anastácio Gonçalves (Lisbon) is composed by glass fragments with different colors and hues (Fig. $1 \mathrm{a}$, Fig. 4).

Blue glasses were used to accomplish part of the window border, some areas of the vegetation in the forest of the central panel, some leaves in the hydrangea plant of the left panel, and the lake on the right panel (Fig. 4). The different hues of the blue color are due to different concentration of cobalt ions, generating the different intensities of the coloration (Fig. 5 a, Fig. 6 a). The blue color in silicate glasses could be attributed to $\mathrm{Co}^{2+}$-ions mainly in tetrahedral coordination, although the contributions due to 5-fold and octahedral complexes can be overlapped modifying the shape and position of the bands $[41,42]$. In tetrahedral coordination, the main band in the visible region is due to the ${ }^{4} \mathrm{~A}_{2} \rightarrow{ }^{4} \mathrm{~T}_{1}(\mathrm{P})$ transition, although two other absorption bands corresponding to ${ }^{4} \mathrm{~A}_{2} \rightarrow{ }^{4} \mathrm{~T}_{2}$ and ${ }^{4} \mathrm{~A}_{2} \rightarrow{ }^{4} \mathrm{~T}_{1}(\mathrm{~F})$ occur in the infrared region. The splitting of the ${ }^{4} A_{2} \rightarrow{ }^{4} T_{1}(P)$ band is caused by a spin-orbit coupling which both splits the ${ }^{4} T_{1}(P)$ 
state and allows the transitions to the neighboring doublet states $\left({ }^{2} A_{1}(G)\right.$ and $\left.{ }^{2} T_{2}(G)\right)$ to gain in intensity $[42,43]$. This electronic transition forms three overlapping bands at 540, 590 and 640 $\mathrm{nm}$ [2]. In addition, $\mathrm{Co}^{2+}$-ions have a high molar extinction coefficient; which means that, even with low concentration, can color the glass with a blue hue.

In the stained-glass window, the blue glasses from the lake presented the best-defined spectra (Fig. 5 a). In this case, the blue flash glasses were acid etched to decrease the thickness of the blue layer diminishing the intensity of the absorption bands, according to the Lambert-Beer Law. The blue of the decorative frame presented the same bands, but the spectrum was less defined due to the high optical density of the color (Fig. 5 a). Very pale blue glasses were also detected on the forest; they presented the same absorption bands due to the high molar extinction coefficient.

The iris flowers and some of the hydrangeas are violet in different hues (Fig. 1 a). The main chromophore of this color is manganese. The most common manganese ions found in silicate glasses are $\mathrm{Mn}^{2+}$ and $\mathrm{Mn}^{3+}$, and they are in equilibrium depending on the temperature and composition of the base glass $[3,41,43,57]$. The $\mathrm{Mn}^{2+}$-ions belong to a $\mathrm{d}^{5}$ configuration, where the electronic transitions are spin-forbidden; therefore, it produces a low-intensity coloration in the visible region $[3,44]$. In contrast, the $\mathrm{Mn}^{3+}$-ions belong to a $\mathrm{d}^{4}$ configuration in octahedral coordination in silicate glass and exhibit a single spin-allowed transition ${ }^{5} \mathrm{Eg} \rightarrow{ }^{5} \mathrm{~T}_{2 \mathrm{~g}}$. This electronic transition presents an intense absorption around $500 \mathrm{~nm}$ in the form of a broad band (Fig. 5 a), due to the splitting of the ground state generated by Jahn-Teller distortion $[1,2,43$ 47]. In addition, the more alkali in the silicate glass, greater is the tendency to absorb oxygen and change into the deeply colored glass [3]. Depending on their concentration, the $\mathrm{Mn}^{3+}$-ions produce a violet color which can vary from pale pink color, normally used in the representation of the human skin [13], to intense mauve or purple, such as in the case of the flowers on the stained-glass window (Fig. 4) [46, 58]. The absorption spectra of the glasses from the woman face and the reddish trees, probably ascribable to the same chromophore, were poorly defined due to their very pale hue and the presence of grisaille (Fig. 6 b).

Regarding the green colors, three different tones were mainly observed on the vegetation represented on the window (plants, tree, grass, and forest) (Fig. 1 a).

The emerald green coloration is due to chromium ions. They can be in two oxidation states, $\mathrm{Cr}^{3+}$ and $\mathrm{Cr}^{6+}$, although the former is the most stable. The typical emerald coloration is due to the blue-green light that transmits the $\mathrm{Cr}^{3+}$-ions and the yellow light transmitted by the $\mathrm{Cr}^{6+}$-ions. The $\mathrm{Cr}^{3+}$-ions, with an electronic configuration $3 \mathrm{~d}^{3}$, presents an octahedral symmetry and 
permits the ${ }^{4} \mathrm{~A}_{2} \rightarrow{ }^{4} \mathrm{~T}_{2}$ (at around $650 \mathrm{~nm}$ ), ${ }^{4} \mathrm{~A}_{2} \rightarrow{ }^{4} \mathrm{~T}_{1}$ (F) (at around $450 \mathrm{~nm}$ ) transitions, together with the transitions to the forbidden states ${ }^{4} \mathrm{~A}_{2} \rightarrow{ }^{2} \mathrm{~T}_{1}(\sim 630 \mathrm{~nm})$ and ${ }^{4} \mathrm{~A}_{2} \rightarrow{ }^{2} \mathrm{E}(\sim 675 \mathrm{~nm})$ (Fig. 5 b). The $\mathrm{Cr}^{6+}$-ions presents a $3 d^{0}$ configuration, that means it does not permit a transition $d \leftrightarrow d$, but produce an intense band centered in the ultraviolet region ( $365 \mathrm{~nm}$ ) which can own a tail in the visible producing a yellow color $[1,41,43]$.

Copper ions usually give a turquoise color on soda-lime silicate glasses. The $\mathrm{Cu}^{2+}$-ions have an electronic configuration $3 d^{9}$ in octahedral coordination, which permits the electronic transition ${ }^{2} \mathrm{E} \rightarrow{ }^{2} \mathrm{~T}_{2}(790 \mathrm{~nm}$ ) (Fig. 5 b). This electronic transition corresponds to a wide single band that presents a significant deformation due to the Jahn-Teller effect. As result, it is produced the pronounced enlargement of one of the octahedral axes which leads to a tetragonal symmetry $[1,2,43]$. This band can be widened giving a dark green color to the glass depending on the copper concentration, the thermal process of glass manufacturing, and, even, the glass alkalinity [1].

Iron ions can also act as green chromophore, but it depends on the equilibrium $\mathrm{Fe}^{3+} / \mathrm{Fe}^{2+}$-ions in the glass. The $\mathrm{Fe}^{2+}$-ions, with a $3 \mathrm{~d}^{6}$ electronic configuration, produce an absorption band at $\mathbf{4 4 0}$ $\mathrm{nm}$ and two more in the infrared region (1100 $\left({ }^{5} \mathrm{~T}_{2} \rightarrow{ }^{5} \mathrm{E}\right)$ and 2100 (distortion splitting) $\mathrm{nm}$ ), whose maxima falls outside the sensitivity range of the human eye $[2,43]$. The wide band at $1100 \mathrm{~nm}$ enters in the visible region and is the responsible for the bluish color. On the other hand, the $\mathrm{Fe}^{3+}$-ions in tetrahedral coordination present the absorption bands at $380\left({ }^{6} \mathrm{~A}_{1} \rightarrow\right.$ $\left.{ }^{4} \mathrm{~T}_{1}(D)\right), 420\left({ }^{6} \mathrm{~A}_{1} \rightarrow{ }^{4} \mathrm{E}(\mathrm{G})\right)$ and $440\left({ }^{6} \mathrm{~A}_{1} \rightarrow{ }^{4} \mathrm{~A}_{1}(G)\right) \mathrm{nm}$ (Fig. 5 b) [1, 2]. These bands can change their intensity depending on the content of alkaline in the glass [48]. The presence of one of the ions predominantly depends on the concentration of iron, the type of glass and the atmosphere during the fusion. As result, iron ions can act as chromophore producing glasses from pale blue to dark yellow.

Not every glass has just one chromophore, glasses can present a mixture of chromophores to expand their color range. This is the case of the turquoise glasses used in some of the tree and bush leaves, in which were detected $\mathrm{CO}^{2+}$ - and $\mathrm{Fe}^{3+}$-ions to obtain a turquoise color (Fig. 5 b, Fig. 6 a).

The previous chromophores $\left(\mathrm{Co}^{2+}, \mathrm{Mn}^{3+}, \mathrm{Cr}^{3+} / \mathrm{Cr}^{6+}, \mathrm{Cu}^{2+}\right.$, and $\left.\mathrm{Fe}^{3+} / \mathrm{Fe}^{2+}\right)$ are ionic species which give the coloration due to the electronic transition of the $d$ electrons in the penultimate electronic layer. However, the warm colors (yellow, orange and red) are due to the presence of nanoparticulates and/or nanocolloidal aggregates, which produce the mechanism of absorption 
and dispersion of the light. The size, the form and the type of nanocolloidal aggregation determine the hue of the glass [1].

An intense yellow and orange were observed on the sky, the platform under the woman and the acanthus leaves in the window border. This coloration is generally obtained by silver staining. Historically, this coloration was made by applying a mixture of silver salts, clays or ochres on one of the glass surfaces and firing them at moderate temperatures $\left(500-650^{\circ} \mathrm{C}\right)$. During firing, there is the ionic exchange between the $\mathrm{Na}^{+}$-ions in the glass surface and the $\mathrm{Ag}^{+}$-ions from the salts, the precipitation of the metallic atoms, and the nanoparticles growth and aggregation. The coloration is generally yellow but, if the thermal treatment is prolonged, a brownish hue can result $[1,5,49-51]$. In silicate glasses, silver staining normally presents an absorption band at $410 \mathrm{~nm}$, but it can be present a slight red-shift $(400-450 \mathrm{~nm})$ depending on the Plasmon resonance of the silver colloids (Fig. 5 c) [14]. The different coloration observed in the sky can be related to the application of different silver salts, which can produce different tones during the thermal treatment. It is also possible that the coloration was due to consecutive thermal treatments, but it could be a longer and riskier process. Regarding the orange glasses from the orange fruits, they were bulk colored, which confirmed the use of high-quality equipment for the firing and annealing process.

Red color was observed in the skirt, some of the hydrangea flowers and the pistils of the flowers from the frame. This color is due to the colloidal dispersion of metallic copper $\left(\mathrm{Cu}^{0}\right)(\mathrm{copper}$ ruby glasses). The copper was added to the glass as $\mathrm{Cu}^{+}$-ions which are linked to the lattice in groups [Si-O-Cu], but, with a heat treatment, react between them to form the metallic nanoparticles [52]. If the thermal treatment is prolonged, the crystals can grow up to particles larger than 1 $\mu \mathrm{m}$, which could give a turbid or opaque appearance [1]. The characteristic copper surface Plasmon resonance produces the dispersion of the light presenting an absorption band at 560 nm (Fig. 5 c).

The brown glasses located in the tree trunks and the lady's corset could be due to amber glass, in which the coloration goes from golden yellow to dark brown. In the iron-amber glasses, the chromophore is formed by a mixed tetrahedral coordination, in which one $\mathrm{Fe}^{3+}$-ion is surrounded by three oxygen ions (bonded to silicon) and one sulfide anion (bonded to alkali ions for preserving electro-neutrality) $\left[\mathrm{FeO}_{3} \mathrm{~S}\right]$. This coordination has an absorption band at $295 \mathrm{~nm}$, due to an electron-transfer between the sulfide and ferric ions, and at $425 \mathrm{~nm}$ (Fig. 5 c) [1]. The color intensity depends on the concentration of $\mathrm{Fe}^{3+}$-ions and $\mathrm{S}^{2-}$-ions, the atmosphere, the alkali 
concentration in the batch, the addition of reductive components such as carbon, and the heat treatment, among others $[1,3,53-55]$.

Finally, the light grayish glass in the clouds and the grass were possibly obtained with a mixture of chromophores, but the low quality of the absorption spectra due to their light pale and the presence of surface grisaille made their identification impossible (Fig. 6 b)
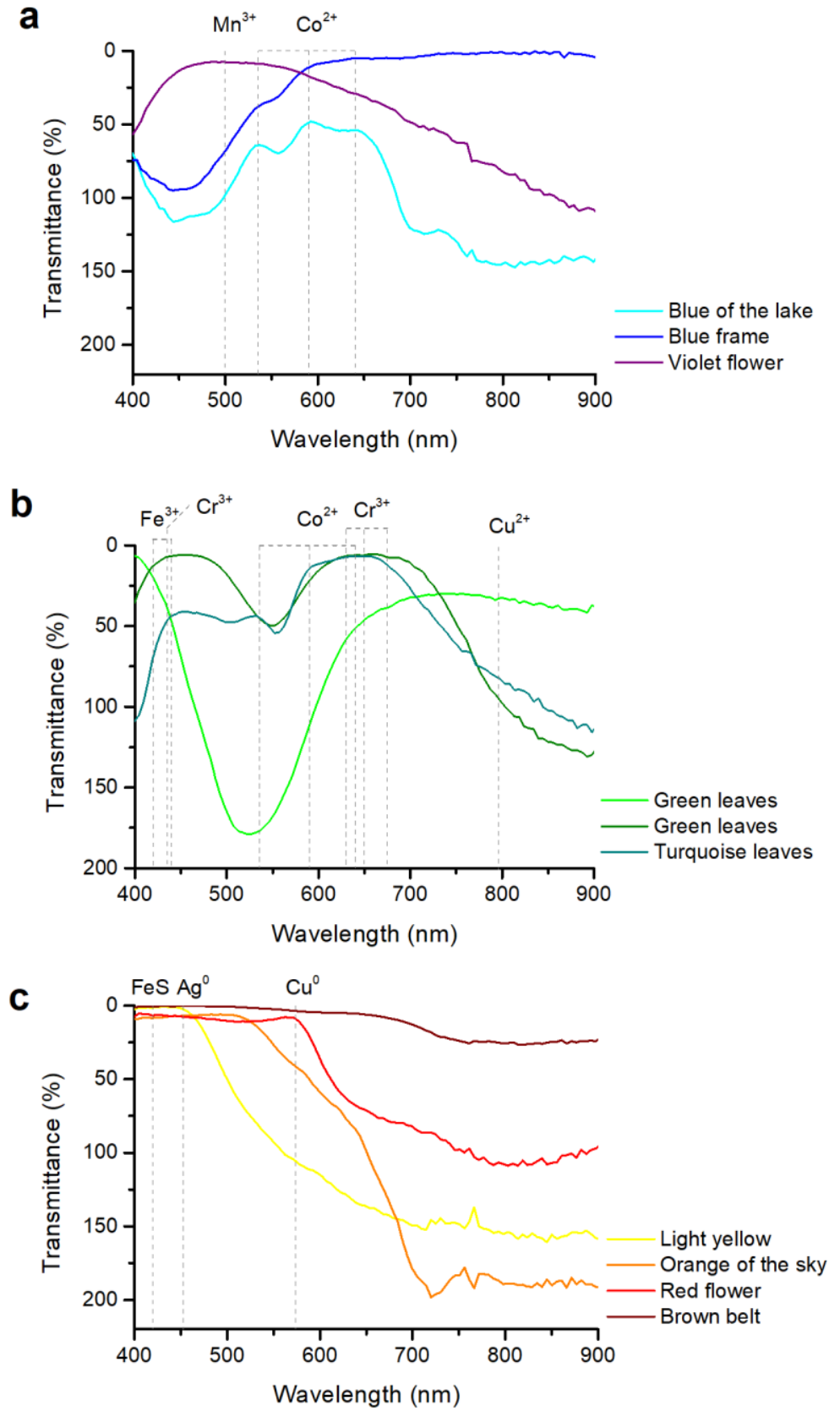

Fig. 5. Transmittance spectra measured by the Visible Hyperspectral Imaging system a) blue and violet glasses, b) green and turquoise glasses, and c) warm-color glasses, from the stained-glass window in the Dining room. The colors of the plotted spectra resume the false colors used in the mapping of Fig. 4 
a

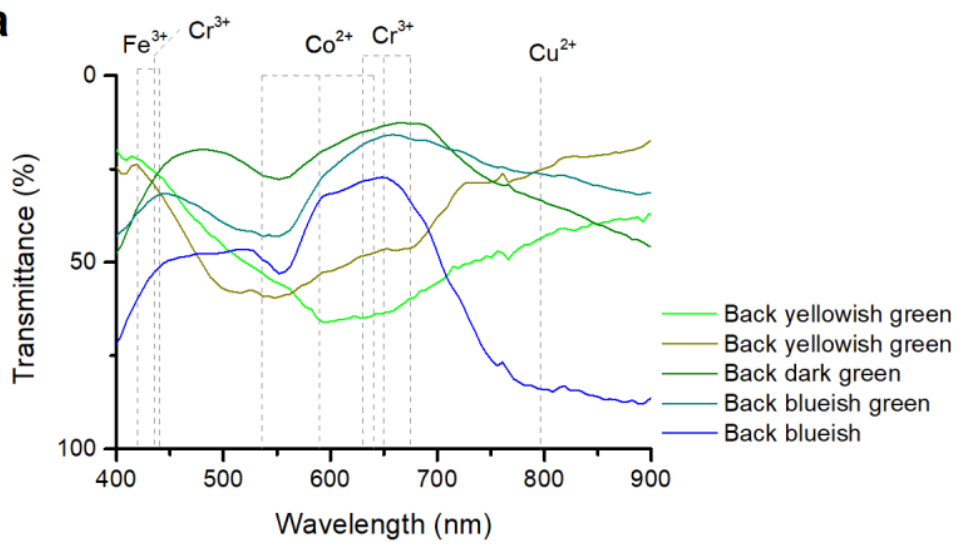

b

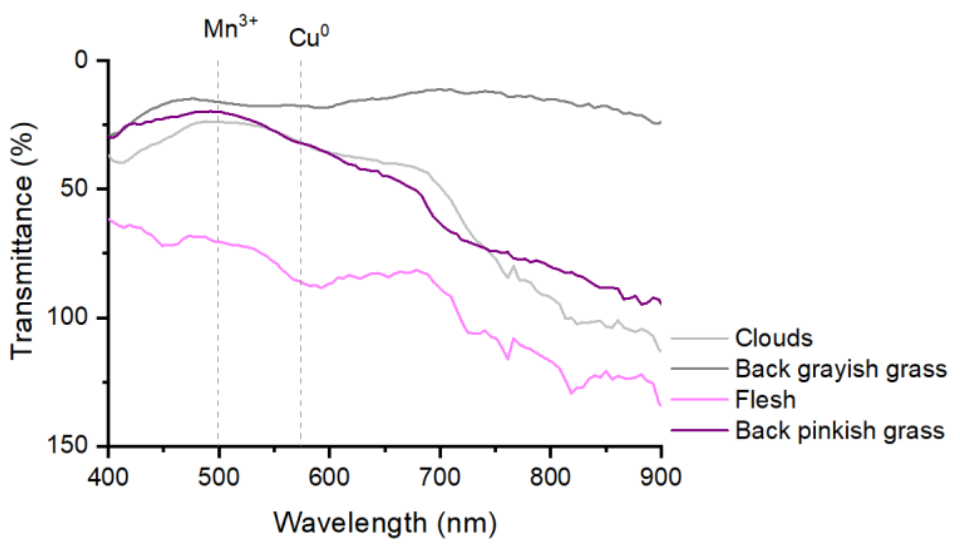

Fig. 6. Transmittance spectra measured by the Visible Hyperspectral Imaging system of the light colors in the background a) bluish and greenish glasses, and b) grayish and reddish glasses, from the stained-glass window in the Dining room. The colors of the plotted spectra resume the false colors used in the mapping of Fig. 4 


\subsubsection{Atelier window}

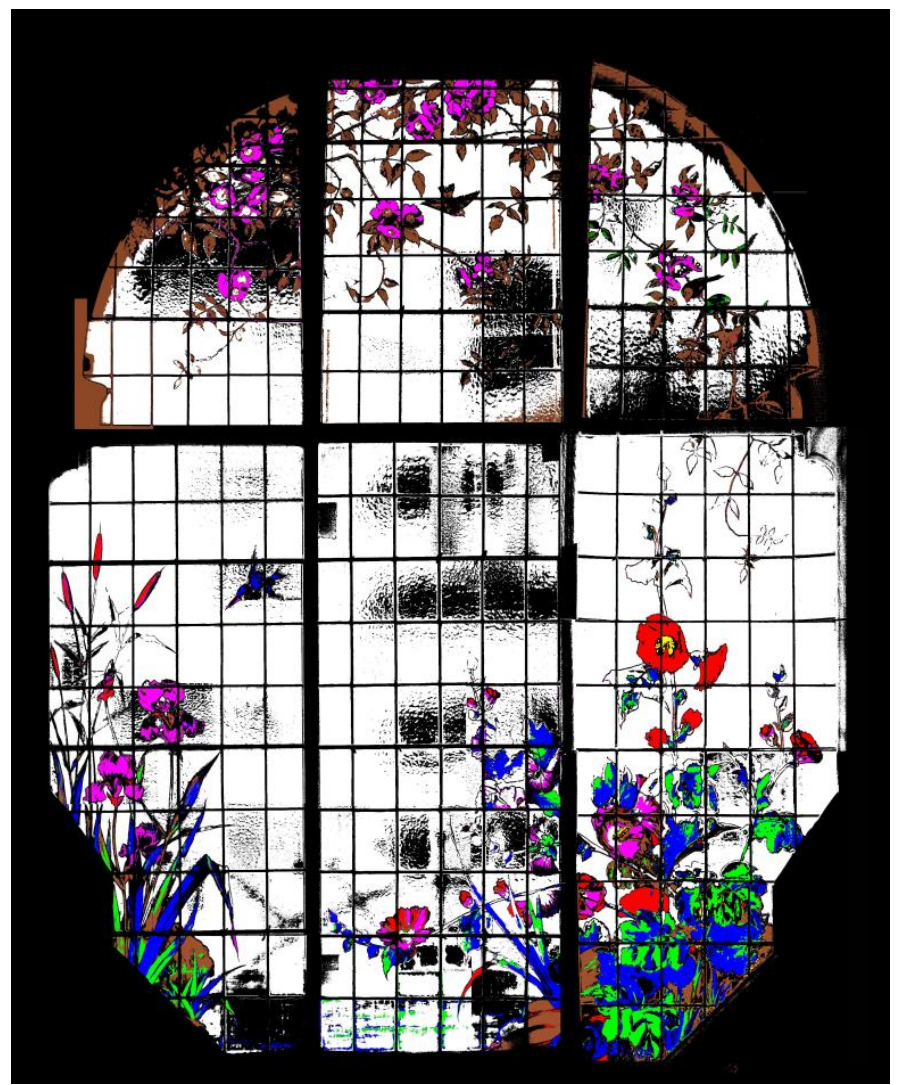

Fig. 7. False-color mapping of the different chromophores in the window panel from the Atelier of the Casa-Museu Dr. Anastácio Gonçalves. Transmittance spectra from each false-color are represented in Fig. 8.

The Atelier window is composed of rectangular uncolored glasses painted with grisaille and enamels. These materials need a low melting point to be fixed to the support glasses and, for this reason, lead glasses were used with/without borax [59-61]. This different glass matrix can affect the local state (coordination and valence) of transition metals ions in the glass matrix and the glass color itself [41].

Contrary to the stained-glass window in the dining room, this panel is darker; especially in the areas near the frame because of both the use of almost opaque paintings and the shadow produced by the architectonical decoration. The unconventional colors observed in the lower part of this panel can be related to probable retouching. These dark areas showed saturated spectra (Fig. 8 a), in which the chromophores were difficult to be identified.

Vegetation in the lower part of the panel presented four different colorations: green, dark green, brown and blue (Fig. 1 b). They showed similar spectra but the relative intensity of the bands is different (Fig. 8 a). 
The blue color was attributed to a cobalt-rich product (Fig. 8 a). Saffre ( $\mathrm{CoO}+$ contaminations) or smalt $\left(\mathrm{SiO}_{2}-\mathrm{K}_{2} \mathrm{O}-\mathrm{CoO}+\right.$ contaminations) were used as colorant in ancient stained-glass enamels, but since 19th century, industrial cobalt-oxide ( $\mathrm{CoO})$ was used to make a dark-blue enamel [60]. The bands in lead glasses appeared in similar positions than in soda-lime silicate glasses; however, their intensity can change due to the different glass basicity (Fig. 8 a) [41, 62, $63]$.

The spectra of green and brownish leaves presented three main bands at around 547, 587 and $632 \mathrm{~nm}$ (Fig. 8 a). The former two maximums correspond to the absorption bands of $\mathrm{Fe}^{3+}$-ions and the latter to the main band of $\mathrm{Cr}^{3+}$-ions [62]. The bands of $\mathrm{Cr}^{3+}$-ions in lead-glasses appeared in a similar position than in soda-lime silicate glasses [62], but their intensity can decrease with the increase of basicity of the glass matrix [41]. On the contrary, the bands of $\mathrm{Fe}^{3+}$-ions are moved to larger wavelengths in rich-lead matrixes [62]. The different colorations of the enamels in the window are due to the presence of different chromophores in different concentrations (Fig. 8 a). Together with these maximums, it is possible to observe the absorption of the glass matrix at low wavelengths (Fig. 8 a), because a high content of lead in the glass favors the movement of the matrix absorption bands into the visible region of the electromagnetic spectrum [62]. Some of the brownish areas detected in the false-color map of the panel, mainly in the upper frame (Fig. 7), were misinterpreted because of the color of the decorative elements of the buildings.

In contrast to the vegetation, the flowers of the Atelier window presented a pinkish-purplish and red color (Fig. 1 b, Fig. 7). The flowers presented their original enamel in a very good state of conservation. The pinkish-purplish color was due to the presence of $\mathrm{Mn}^{3+}$-ions in the enamels (Fig. 8 b). It is interesting that, even when the color is apparently similar to the other window, the shape of the spectra is completely different. The change in the base glass influenced the atomic surroundings and moved the absorption band to higher wavelengths (Fig. 8 b). The color variations were also motivated by the addition of other chromophores to the enamel such as copper or cobalt oxide (Fig. 8 b) [60].

The red flowers presented the characteristic spectrum of the Plasmon resonance of the copper colloids (Fig. 8 b), and the yellow pistils of the flowers were made by the silver staining with nanoparticles of silver on the uncolored support glasses. These areas showed the band characteristic of the Plasmon resonance of the silver colloids at $415 \mathrm{~nm}$, together with a low contribution of the Plasmon resonance of the copper colloids at $552 \mathrm{~nm}$ due to the proximity of the pistils to the petals (Fig. 8 b). 


\section{a}
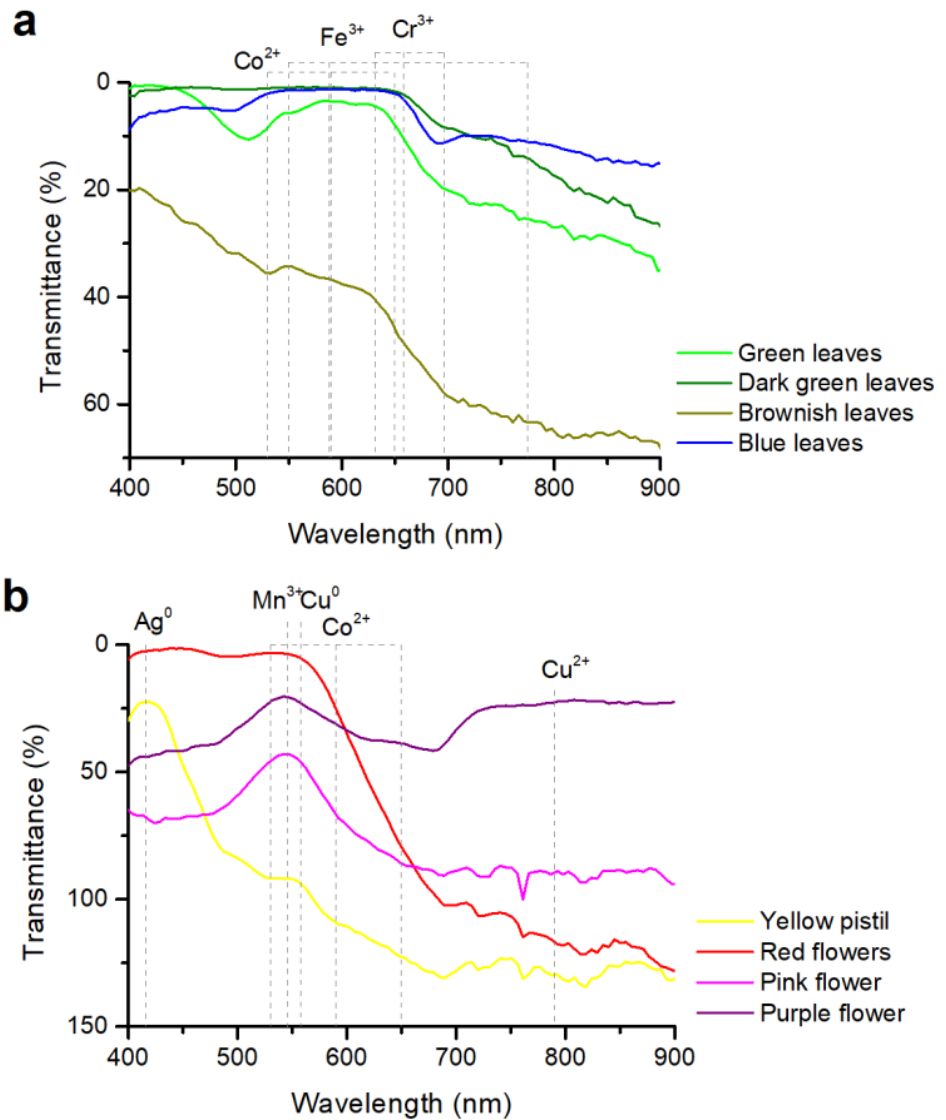

Fig. 8. Transmittance spectra measured by the Visible Hyperspectral Imaging system for a) Blue, green and brown glasses, b) Yellow, red, and purple glasses, from the window panel in the Atelier. The colors of the plotted spectra resume the false colors used in the mapping of Fig. 7

\section{Conclusions}

This study showed the implementation of the methodology for the in-situ characterization of the glass color in the stained-glass windows from the Casa-Museu Dr. Anastácio Gonçalves (Lisbon, Portugal) by Visible Hyperspectral Imaging. The great novelty of the work was the use of natural sunlight as illumination. The main disadvantage of this methodology was the variation in the intensity of the sunlight during the day, which significantly affected the spectral transmittance. Nevertheless, this interference did not affect the spectral features of each different color that allowed the identification of the chromophores. Concerning the glass color, highly saturated spectra were difficult to interpret and light colors were affected significantly by external features.

Regarding the analysis of the stained-glass windows, the Dining Room glass window present glasses colored in bulk with iron, manganese, cobalt, copper, and chromium; silver staining, copper ruby and iron-amber glasses were also detected to create the warm colors. The Atelier panel was made with uncolored glasses painted with grisaille and enamels; the chromophores 
of these paintings were iron, manganese, cobalt, copper, and chromium; however, they showed wavelength shiftings due to the high content of lead and/or borax in the glass painting matrixes.

\section{Acknowledgments}

The authors thank Dr. T. Marques and Dr. A. Mântua (Casa-Museu Dr. Anastácio Gonçalves, Lisbon, Portugal) for the facilities provided to accomplish this research and B. Doherty (SMAArt Centre and CNR-ISTM, Perugia, Italy) for the manuscript revision. This work has been funded collectively by the Access to Research Infrastructures activity in the Horizon 2020 Programme of the EU (IPERION CH Grant Agreement n. 654028), the Fundação para a Ciência e a Tecnologia de Portugal (Project ref. UID/EAT/00729/2019) and Fundación General CSIC (ComFuturo Programme).

\section{Bibliography}

[1] J.M. Fernández Navarro, El vidrio, 3rd ed., Consejo Superior de Investigaciones Científicas, Madrid, 2003.

[2] D. Möncke, M. Papageorgiou, A. Winterstein-Beckmann, N. Zacharias, Roman glasses coloured by dissolved transition metal ions: redox-reactions, optical spectroscopy and ligand field theory, J. Archaeol. Sci., 46 (2014) 23-36. https://doi.org/10.1016/i.jas.2014.03.007

[3] W.A. Weyl, Coloured glasses, Society of Glass Technology, Sheffield, England, 1967.

[4] N. Carmona, M. García Heras, M.Á. Villegas Broncano, C. Gil, Vidrios y grisallas del s. XV de la Cartuja de Miraflores (Burgos): Caracterización y estado de conservación, Bol. Soc. Esp. Ceram. V., 44 (2005) 251-258.

[5] J. Delgado, M. Vilarigues, A. Ruivo, V. Corregidor, R.C.d. Silva, L.C. Alves, Characterisation of medieval yellow silver stained glass from Convento de Cristo in Tomar, Portugal, Nucl. Instrum. Meth. B, 269 (2011) 2383-2388. https://doi.org/10.1016/i.nimb.2011.02.059

[6] M. Vilarigues, P. Fernandes, L.C. Alves, R.C. da Silva, Stained glasses under the nuclear microprobe: A window into history, Nucl. Instrum. Meth. B, 267 (2009) 2260-2264. https://doi.org/10.1016/i.nimb.2009.03.049

[7] P. Fernandes, M. Vilarigues, L.C. Alves, R.C. da Silva, Stained glasses from Monastery of Batalha: Non-destructive characterisation of glasses and glass paintings, J. Cult. Herit., 9 (2008) e5-e9. https://doi.org/10.1016/i.culher.2008.07.005

[8] A. Ceglia, W. Meulebroeck, H. Wouters, K. Baert, K. Nys, H. Terryn, H. Thienpont, Using optical spectroscopy to characterize the material of a 16th c. stained glass window, Proc. SPIE 8422, 84220A (2012) 1-12. https://doi.org/10.1117/12.981436

[9] W. Meulebroeck, H. Wouters, K. Nys, H. Thienpont, Authenticity screening of stained glass windows using optical spectroscopy, Sci. rep., 6 (2016) 37726-37726. https://doi.org/10.1038/srep37726

[10] T. Palomar, La interacción de los vidrios históricos con medios atmosféricos, acuáticos y enterramientos. PhD dissertation, Universidad Aunónoma de Madrid (Spain), 2013.

[11] T. Palomar, M. García Heras, M.A. Villegas, Archaeological and historical glasses: A bibliometric study, Bol. Soc. Esp. Ceram. V., 48 (2009).

[12] G. Molina, S. Murcia, J. Molera, C. Roldan, D. Crespo, T. Pradell, Color and dichroism of silver-stained glasses, J. Nanopart. Res., 15 (2013) 1932. https://doi.org/10.1007/s11051-013$\underline{1932-7}$

[13] T. Palomar, Chemical composition and alteration processes of glasses from the Cathedral of León (Spain), Bol. Soc. Esp. Ceram. V., $57 \quad$ (2018) 101-111. https://doi.org/10.1016/i.bsecv.2017.10.001 
[14] T. Palomar, F. Agua, M. García-Heras, M.A. Villegas, Chemical degradation and chromophores of 18th century window glasses, Glass Technol., 52 (2011) 145-153.

[15] M. García-Heras, N. Carmona, C. Gil, M.A. Villegas, Neorenaissance/Neobaroque stained glass windows from Madrid: a characterisation study on some panels signed by the Maumejean Fréres company, J. Cult. Herit., 6 (2005) 91-98. https://doi.org/10.1016/j.culher.2004.12.001

[16] M. Bacci, M. Picollo, Non-destructive spectroscopic detection of cobalt(II) in paintings and glass, Stud. Conserv., 41 (1996) 136-144. https://doi.org/10.1179/sic.1996.41.3.136

[17] A. Orlando, F. Olmi, G. Vaggelli, M. Bacci, Mediaeval stained glasses of Pisa Cathedral (Italy): their composition and alteration products, Analyst, 121 (1996) 553-558.

[18] T. Palomar, Guía rápida para estudiar el color de un vidrio, MoleQla, (2016) 33-35.

[19] M. Hunault, G. Lelong, M. Gauthier, F. Gélébart, S. Ismael, L. Galoisy, F. Bauchau, C. Loisel, G. Calas, Assessment of transition element speciation in glasses using a portable transmission ultraviolet-visible-near-infrared (UV-Vis-NIR) spectrometer, Appl. Spectrosc., 70 (2016) 778784. https://doi.org/10.1177/0003702816638236

[20] W. Meulebroeck, K. Baert, H. Wouters, P. Cosyns, A. Ceglia, S. Cagno, K. Janssens, K. Nys, H. Terryn, $\mathrm{H}$. Thienpont, The identification of chromophores in ancient glass by the use of UV-VISNIR spectroscopy, Proc. SPIE 7726, 77260D (2010) 1-12. https://doi.org/10.1117/12.853666

[21] E. Rebollo, F. Ratti, G.M. Cortelazzo, L. Poletto, R. Bertoncello, New trends in imaging spectroscopy: the non-invasive study of the Scrovegni Chapel stained glass windows, Proc. SPIE 8084, 808407 (2011) 1-10. https://doi.org/10.1117/12.888839

[22] M. Bacci, A. Corallini, A. Orlando, M. Picollo, B. Radicati, The ancient stained windows by Nicolò di Pietro Gerini in Florence. A novel diagnostic tool for non-invasive in situ diagnosis, J. Cult. Herit., 8 (2007) 235-241. https://doi.org/10.1016/j.culher.2007.02.001

[23] C.B. Azzoni, D.d. Martino, V. Marchesi, B. Messiga, M.P. Riccardi, Colour attributes of medieval window panes: electron paramagnetic resonance and probe microanalyses on stained glass windows from Pavia Carthusian Monastery, Archaeometry, 47 (2005) 381-388. https://doi.org/10.1111/j.1475-4754.2005.00208.x

[24] L. Van Wersch, C. Loisel, F. Mathis, D. Strivay, S. Bully, Analyses of early Medieval stained window glass from the Monastery of Baume-Les-Messieurs (Jura, France), Archaeometry, 58 (2016) 930-946. https://doi.org/10.1111/arcm.12207

[25] B. Gómez, M.A. Respaldiza, A. De Pablos, I. Ortega, F. Capel, F.J. Valle Fuentes, M.P. Alonso, Caracterización de un vidrio rojo medieval procedente de las vidrieras del Monasterio de las Huelgas de Burgos, Bol. Soc. Esp. Ceram. V., 48 (2009) 179-186.

[26] D. Gimeno, M. Aulinas, F. Bazzocchi, J. Fernández-Turiel, M. García-Valles, D. Novembre, E. Basso, B. Messiga, M. Ricacardi, C. Tarozzi, Caracterización química de la vidriera del rosetón del Duomo de Siena (Italia, 1288-1289), Bol. Soc. Esp. Ceram. V., 49 (2010) 205-213.

[27] D. Gimeno, M. Garcia-Valles, J.L. Fernandez-Turiel, F. Bazzocchi, M. Aulinas, M. Pugès, C. Tarozzi, M.P. Riccardi, E. Basso, C. Fortina, M. Mendera, B. Messiga, From Siena to Barcelona: Deciphering colour recipes of Na-rich Mediterranean stained glass windows at the XIII-XIV century transition, J. Cult. Herit., 9 (2008) e10-e15. https://doi.org/10.1016/i.culher.2008.08.001

[28] S. Alberta, M. Gianmario, P. Valentina, The stained glass window of the southern transept of St. Anthony's Basilica (Padova, Italy): study of glasses and grisaille paint layers, Spectrochim. Acta B, 66 (2011) 81-87. https://doi.org/10.1016/i.sab.2010.11.015

[29] M. Hunault, F. Bauchau, C. Loisel, M. Hérold, L. Galoisy, M. Newville, G. Calas, Spectroscopic investigation of the coloration and fabrication conditions of medieval blue glasses, J. Am. Ceram. Soc., 99 (2016) 89-97. https://doi.org/10.1111/jace.13783

[30] S. Singh, A. Kumar, Absorption spectrum of $\mathrm{Mn}^{3+}$ and redox equilibria of iron and manganese in sodium silicate glass, Phys. Chem. Glasses, 33 (1992) 61-67.

[31] B. Mirhadi, B. Mehdikhani, Effect of manganese oxide on redox iron in sodium silicate glasses, J. Optoelectron. Adv. M., 13 (2011) 1309-1312. 
[32] G. Van der Snickt, S. Legrand, J. Caen, F. Vanmeert, M. Alfeld, K. Janssens, Chemical imaging of stained-glass windows by means of macro X-ray fluorescence (MA-XRF) scanning, Microchem. J., 124 (2016) 615-622. https://doi.org/10.1016/i.microc.2015.10.010

[33] J. Caen, S. Legrand, G. van der Snickt, K. Janssens, Macro X-ray fluorescence (MA-XRF) scanning: a new and efficient method for documenting stained-glass panels, in: Le vitrail: comment prendre soin d'un patrimoine fragile? 9e Forum sur la conservation et la technologie du vitrail, Paris, 8-10 juillet 2015, ICOMOS France, Corpus Vitrearum, Laboratoire de recherche des monuments historiques, France, 2015, pp. 74-81.

[34] E. Bernady, Kami, M. ska, M. otek, M. Walczak, gorzata, The investigation of 15th century paint layers on two stained glass windows from the Dominican Monastery in Krakow, Poland, Glass Technol., 59 (2018) 46-53.

[35] L. de Viguerie, S. Rochut, M. Alfeld, P. Walter, S. Astier, V. Gontero, F. Boulc'h, XRF and reflectance hyperspectral imaging on a 15th century illuminated manuscript: combining imaging and quantitative analysis to understand the artist's technique, Herit. Sci., 6 (2018) 11. https://doi.org/10.1186/s40494-018-0177-2

[36] J.K. Delaney, J.G. Zeibel, M. Thoury, R. Littleton, M. Palmer, K.M. Morales, E.R.d.I. Rie, A. Hoenigswald, Visible and Infrared Imaging Spectroscopy of Picasso's Harlequin Musician: Mapping and Identification of Artist Materials in Situ, Appl. Spectrosc., 64 (2010) 584-594. https://doi.org/10.1366/000370210791414443

[37] T. Vitorino, A. Casini, C. Cucci, M.J. Melo, M. Picollo, L. Stefani, Hyper-Spectral acquisition on historically accurate reconstructions of red organic lakes, in: A. Elmoataz, O. Lezoray, F. Nouboud, D. Mammass (Eds.) Conference proceedings of the ICISP 2014: Image and Signal Processing, Springer International Publishing, Switzerland, 2014, pp. 257-264.

[38] M. Alfeld, M. Mulliez, J. Devogelaere, L. de Viguerie, P. Jockey, P. Walter, MA-XRF and hyperspectral reflectance imaging for visualizing traces of antique polychromy on the Frieze of the Siphnian Treasury, Microchem. J., 141 (2018) 395-403. https://doi.org/10.1016/i.microc.2018.05.050

[39] F. Pottier, A. Michelin, S. Kwimang, C. Andraud, F. Goubard, B. Lavédrine, Macroscopic reflectance spectral imaging to reveal multiple and complementary types of information for the non-invasive study of an entire polychromatic manuscript, J. Cult. Herit., (2018). https://doi.org/10.1016/j.culher.2018.06.001

[40] E. Pouyet, S. Devine, T. Grafakos, R. Kieckhefer, J. Salvant, L. Smieska, A. Woll, A. Katsaggelos, O. Cossairt, M. Walton, Revealing the biography of a hidden medieval manuscript using synchrotron and conventional imaging techniques, Anal. Chim. Acta, 982 (2017) 20-30. https://doi.org/10.1016/i.aca.2017.06.016

[41] A. Terczynska-Madej, K. Cholewa-Kowalska, M. Laczka, The effect of silicate network modifiers on colour and electron spectra of transition metal ions, Opt. Mater., 32 (2010) 14561462. https://doi.org/10.1016/i.optmat.2010.05.024

[42] C. Fornacelli, A. Ceglia, S. Bracci, M. Vilarigues, The role of different network modifying cations on the speciation of the $\mathrm{Co2}+$ complex in silicates and implication in the investigation of historical glasses, Spectrochim. Acta A, 188 (2018) 507-515. https://doi.org/10.1016/i.saa.2017.07.031

[43] A. Paul, Chemistry of Glasses, Second ed., Chapman and Hall, London, 1990.

[44] R.P. Sreekanth Chakradhar, G. Sivaramaiah, J.L. Rao, N.O. Gopal, EPR and optical investigations of manganese ions in alkali lead tetraborate glasses, Spectrochim. Acta A, 62 (2005) 761-768. https://doi.org/10.1016/j.saa.2005.02.045

[45] A. Terczyńska-Madej, K. Cholewa-Kowalska, M. Łączka, Coordination and valence state of transition metal ions in alkali-borate glasses, Opt. Mater., 33 (2011) 1984-1988. https://doi.org/10.1016/j.optmat.2011.03.046

[46] C. Nelson, W.B. White, Transition metal ions in silicate melts-I. Manganese in sodium silicate melts, Geochim. Cosmochim. Ac., 44 (1980) 887-893. https://doi.org/10.1016/0016$\underline{7037(80) 90269-0}$ 
[47] N. Srisittipokakun, C. Kedkaew, J. Kaewkhao, P. Limsuwan, Coloration in Soda-Lime-Silicate Glass System Containing Manganese, Adv. Mat. Res., 93-94 (2010) 206-209. https://doi.org/10.4028/www.scientific.net/AMR.93-94.206

[48] K.E. Fox, T. Furukawa, W.B. White, Transition metal ions in silicate melts. Part 2. Iron in sodium silicate glasses, Phys. Chem. Glasses, 23 (1982) 169-178.

[49] D. Jembrih-Simbürger, C. Neelmeijer, O. Schalm, P. Fredrickx, M. Schreiner, K. De Vis, M. Mäder, D. Schryvers, J. Caen, The colour of silver stained glass-analytical investigations carried out with XRF, SEM/EDX, TEM, and IBA, J. Anal. Atom. Spectrom., 17 (2002) 321-328. https://doi.org/10.1039/B111024C

[50] S. Pérez-Villar, J. Rubio, J.L. Oteo, Study of color and structural changes in silver painted medieval glasses, J. Non-Cryst. Solids, $354 \quad$ (2008) 1833-1844. https://doi.org/10.1016/j.jnoncrysol.2007.10.008

[51] M.C. Özdemir Yanık, M. Sarıgüzel, Y. Öztürk, T. Yıldız, E.D. Kaçar, A. İyiel, B. İzmirlioğlu, E. Günay, Influence of different process conditions on mechanical, optical and surface properties of silver ion exchanged soda-lime silicate glass, J. Non-Cryst. Solids, 493 (2018) 1-10. https://doi.org/10.1016/i.jnoncrysol.2018.04.024

[52] O. Véron, J.P. Blondeau, D.D.S. Meneses, C.A. Vignolle, Characterization of silver or copper nanoparticles embedded in soda-lime glass after a staining process, Surf. Coat. Tech., 227 (2013) 48-57. https://doi.org/10.1016/j.surfcoat.2012.10.014

[53] R.G.C. Beerkens, Amber chromophore formation in sulphur-and iron-containing soda-limesilica glasses, Glass Sci. Technol., 76 (2003) 166-175.

[54] R.G.C. Beerkens, K. Kahl, Chemistry of sulphur in soda-lime-silica glass melts, Phys. Chem. Glasses, 43 (2002) 189-198.

[55] R. Falcone, S. Ceola, A. Daneo, S. Maurina, The role of sulfur compounds in coloring and melting kinetics of industrial glass, Rev. Mineral. Geochem., 73 (2011) 113-141. https://doi.org/10.2138/rmg.2011.73.5

[56] J.K. Delaney, J.G. Zeibel, M. Thoury, R. Littleton, K.M. Morales, M. Palmer, E.R. de la Rie, Visible and infrared reflectance imaging spectroscopy of paintings: pigment mapping and improved infrared reflectography, Proc. SPIE 7391, 739103 (2009) 1-8. https://doi.org/10.1117/12.827493

[57] A. Gaddam, H.R. Fernandes, D.U. Tulyaganov, M.J. Pascual, J.M.F. Ferreira, Role of manganese on the structure, crystallization and sintering of non-stoichiometric lithium disilicate glasses, RSC Adv., 4 (2014) 13581-13592. https://doi.org/10.1039/C3RA46393A

[58] N. Srisittipokakun, K. Kirdsiri, J. Kaewkhaoi, C. Kedkaewdan, P. Limsuwan, Absorption and coloration of $\mathrm{MnO}_{2}$ doped in soda-lime-silicate and soda-lime-borate glasses, Procedia Engineer., 8 (2011) 261-265. https://doi.org/10.1016/j.proeng.2011.03.048

[59] C. Machado, A. Machado, T. Palomar, M. Vilarigues, Grisaille in historical written sources, J. Glass Stud., (In press).

[60] O. Schalm, V. Van der Linden, P. Frederickx, S. Luyten, G. Van der Snickt, J. Caen, D. Schryvers, K. Janssens, E. Cornelis, D. Van Dyck, M. Schreiner, Enamels in stained glass windows: Preparation, chemical composition, microstructure and causes of deterioration, Spectrochim. Acta B, 64 (2009) 812-820. https://doi.org/10.1016/j.sab.2009.06.005

[61] C. Machado, A. Machado, T. Palomar, L.C. Alves, M. Vilarigues, Debitus grisailles for stainedglass conservation: an analytical study, Conservar Património, (in press). https://doi.org/10.14568/cp2018067

[62] E. Baiocchi, A. Montenero, M. Bettinelli, A. Sotgiu, Optical and magnetic properties of firstrow transition metal ions in lead-silicate glass, J. Non-Cryst. Solids, 46 (1981) 203-215. https://doi.org/10.1016/0022-3093(81)90161-7.

[63] M. Hunault, G. Calas, L. Galoisy, G. Lelong, M. Newville, Local ordering around tetrahedral $\mathrm{Co}^{2+}$ in silicate glasses, J. Am. Ceram. Soc., 97 (2014) 60-62. https://doi.org/10.1111/jace.12709 